\title{
Coal cluster as a structural factor in the development of Kuzbass
}

\author{
Yuri Fridman ${ }^{1,2 *}$, Galina Rechko $^{1,2}$, and Olesya Khokhrina $^{3}$ \\ ${ }^{1}$ Institute of Economics and Industrial Engineering of the Siberian Branch of the Russian Academy of \\ Sciences, 630090 Novosibirsk, 17 Acad. Lavrentyev Av., Russian Federation \\ ${ }^{2}$ T.F. Gorbachev Kuzbass State Technical University, 650000 Kemerovo, 28 Vesennyaya st., Russian \\ Federation \\ ${ }^{3}$ Kemerovo State University, 650000 Kemerovo, 6 Krasnaya st., Russian Federation
}

\begin{abstract}
The article contains the results of the analysis of dynamics and structural transformations of employment and production of gross value added (GVA), carried out by the authors on the material of Kuzbass. The study was carried out using the shift-share analysis for 2007-2018. We can state that the employment dynamics, which was negative during this period, was determined primarily by regional factors. The dynamics of GVA was influenced by national (positive) and regional (negative) factors. The contribution of structural shifts to the growth of GVA over the past decade was negative and insignificant, and the decline in the number of employed occurred with a scarcely changed employment pattern. The coal cluster remains the core of the Kuzbass economy and retains the status of its most efficient sector - there are no obvious candidates for the role of a new leader. Meanwhile, the high dependence of the coal industry on external macroeconomic conditions, fluctuations in world markets, makes the strategic outlook of the entire region's economy vulnerable and unstable. Therefore, it is important to find and implement such model of the socio-economic transformation of Kuzbass, which will help protect and ensure the stability of the region for decades to come.
\end{abstract}

\section{Introduction}

In terms of many indicators of the business environment, Kuzbass (the Kemerovo Region) today is inferior to the average level in Russia and a number of neighboring Siberian regions. The peculiarity of the Kemerovo Region is that the coal industry is still the most efficient both in terms of the level of production of gross value added (GVA) and other indicators of development efficiency (financial performance, capital intensity, budget effectiveness per job) [1].

However, the regional dynamics and sustainability of the development of the coal industry in Kuzbass are mainly determined by external factors, primarily the demand and the coal prices in the world markets, which is one of the key problems of its development. Therefore, the modernization of the regional economy, which implies a decrease in the share of primary industries and an increase in the production of products with a higher added value, is one of the strategic priorities of the Kemerovo Region. This variant for diversifying the sectoral structure should solve at least two problems: firstly, to cushion price shocks in the coal industry, and secondly, to facilitate the efficient flow of labor between different sectors of the economy. All this is ultimately designed to ensure the transformation of the socio-economic system of Kuzbass.

\footnotetext{
${ }^{*}$ Corresponding author: yurifridman@mail.ru
} 


\section{Materials and Methods}

The study of topical problems of the Kuzbass economy was based on the analysis of official strategic planning documents and data from the Federal State Statistics Service (Rosstat). To assess the structural factors of economic development in the Kemerovo region, the method of shift-share analysis [2-5] was used - a method of quantitative analysis of structural changes in the regional economy, measured by the dynamics of employment indicators (the period of 2007-2018 was taken for calculations) and the dynamics of indicators of generation of gross value added (comparable data are calculated for 20072016 in 2008 prices).

\section{Results and Discussion}

Based on the method of shift-share analysis, the authors analyzed the employment dynamics and structural transformations and generation of gross value added in the Kemerovo region - Kuzbass. As a result, it was revealed that the sectoral structure of these indicators for ten years (2007-2018) scarcely changed. At the same time, the employment dynamics, and it was negative, was predetermined mainly by regional factors, which together determine the specifics of the region. The following fact is important: the number of employed in Kuzbass reduced with an almost unchanged structure of the regional economy - the index of relative structural changes of A. Salai was only about 0.175 (the range of its change is from 0 to 1: the larger the value, the stronger the differences in the structure).

Structural changes in the generation of gross value added, calculated in constant prices, also turned out to be small for the Kuzbass economy: the value of the index of relative structural changes in GVA was at the level of 0.116, which is comparable with the corresponding indicator for the employment pattern. At the same time, in contrast to employment, the trends in the generation of gross value added in the Kemerovo region were set by both national (positive contribution) and regional (negative effect) factors. The contribution of the structural factor to the GVA growth was negative and insignificant. That is, over the ten years under consideration, there have been no major advances in the Kuzbass region in the modernization both of the structure of gross value added generation and the employment pattern. In other words, if the transformation of the system is perceived as a progressive transformation of its structure, which is caused by a change in its structural elements, which goes beyond the possibilities of self-organization of the system at the previous level, then there is no need to talk about any transformation of the socioeconomic system of the Kemerovo region in this case.

The results of the analysis of the number of employed and the GVA dynamics indicate that the region has been outside the main development trends of the Russian economy all these years. Moreover, there are grounds to state that the structure of the economy, which was formed during the Soviet era, and the features inherited by it since then, continue to determine the dynamics of the Kemerovo Region's development and serve as a strategic challenge for the region.

The coal cluster continues to be the dominant feature of the economy of the Kuzbass region (a large local complex that includes enterprises that specialize in coal mining and processing, as well as service organizations of various types of activity). Moreover, the influence of this segment on the regional economy demonstrates positive dynamics within the decade, which became the object of the authors' attention. Calculations based on official statistics show: in 2007-2017, the share of the coal industry in the gross regional product of the Kemerovo region increased by more than 12 percentage points (pp) and exceeded $35 \%$, the share of the industry exceeded $40 \%$ in the fixed assets of the Kuzbass economy ( + about 
$12 \mathrm{pp})$, the contribution of coal in the generation of incomes of the consolidated budget of the region increased to $36.8 \%$ (+ almost $14 \mathrm{pp}$ ). Over the same period, the coal industry has strengthened its position as a center of attraction for investment in fixed assets - over $50 \%$ of investments in the regional economy, and as a major exporter - almost $80 \%$ of Kuzbass exports.

At the current stage, the location quotient of the coal mining industry in the Kemerovo region are many times (more than 30 times) higher than the lower limit of identification of the basic industries of the regional economy (1.25). There are two more basic industrial heavyweights in Kuzbass - metallurgy and energy. In the group of industries of the current specialization of the region (the location quotient exceeds 1.0) there are chemical industry, mechanical engineering, construction materials industry, health care and education. But there are no obvious candidates for the role of a new leader in the Kuzbass economy.

As a result, the Kemerovo Region is currently an example of an "old industrial region", the "industry core" of which is formed by industries that are at the industrial stage of development. Moreover, the coal industry, which is backbone of the regional economy, is strongly influenced by external macroeconomic conditions, as a result of which the strategic outlook of the entire region's economy is vulnerable and unstable. The situation is aggravated by the lack of an effective infrastructure for transforming the development of basic industries - primarily the coal industry - into the general economic development of the region. The system that existed during the Soviet period has exhausted, and since the early 1990s the Kemerovo region is looking for an adequate replacement for it. Although the coal industry generates financial resources, it is not capable of providing the Kuzbass region with sustainable growth [6-7].

Today, taxes are the main formalized tool for transforming the financial resources generated by coal into the development of the territory. In Russia, taxation of the coal industry is based on gross indicators (revenue, production and export of coal products). And the main body of revenues is generated by the profit tax, the value of which, due to the export-oriented model of the Russian coal business, directly depends on the cyclical fluctuations on world markets [8]. For example, in 2015, the coal industry enterprises paid 8 billion rubles of income tax to the consolidated budget of Kuzbass with coal production of 215 million tons, in 2017 - more than 25 billion rubles with coal production of 240 million tons. At the same time, other types of taxes scarcely depend on the production rate. In 2010, while mining 185 million tons of coal, the mineral extraction tax amounted to four billion rubles, and in 2017 - six billion rubles with coal production of 240 million tons.

In 2020, the global crisis in the coal industry [9-10] (low prices and reduced production volumes) and the global lockdown (due to the coronavirus pandemic) [11-12] led to the fact that Kuzbass (coal production in the region in 2020 decreased by $12 \%$ to 220 million tons) faced a tangible drop in budget revenues, primarily on profit and mineral extraction taxes, and personal income tax revenues fell as well. The regional budget for 2021 was a priori planned with a deficit of more than $10 \%$.

An important role in a synergistic effect from the development of the coal industry for the regional economy is played by the location quotient, the involvement of local businesses in the supply chain of goods and services for the anchor mining industry. The location quotient in the Kemerovo region is now quite low: according to the calculations of a number of experts [13], it does not exceed $10 \%$. With the annual volume of purchases of coal companies in Kuzbass in the amount of about 400 billion rubles, products of regional origin are only 40-45 billion rubles. Another 4-5 billion rubles of regional products are uncompetitive and, due to high prices or low quality, are not in demand from the coal business. The location quotient in Kuzbass is not regulated by license agreements or regional laws. There are only very controversial attempts to solve the problem by creating a mining engineering cluster in the region. 
Since the beginning of the 2000s the authorities of the Kemerovo region promoted the idea of creating a coal chemistry cluster in the region with the aim of organizing the production of high value-added products from coal on the territory of Kuzbass. However, the lack of active interest of business and the state in the coal chemistry industry, as well as the low competitiveness of coal in comparison with oil and gas as raw materials for the production of a wide range of chemical products, cast doubt on the possibility of rapid development of the Kuzbass coal chemistry cluster, and therefore, in general, the option of modernization the regional economy through the coal chemistry reloading of the coal industry [14].

\section{Conclusion}

Based on the results of the analysis, the following conclusion can be drawn: the way of intensifying the development of the coal industry, which the Kemerovo Region has followed over the past decades, did not help develop higher value-added production in the region, as well as service industries. The launch of the mechanism for diversifying the economy has also not yet yielded the desired result: it has not been possible to create such an economic structure in the region that would be resistant to external shocks. In turn, the proposed options for upgrading the coal cluster turned out to be rather weak and do not have sufficient potential to stimulate the process of transformation of the entire socioeconomic system of the region. So, the discussion about the future of the coal region continues. And we believe that the primary task today is to create workable mechanisms for using coal rental income for the reconstruction of the economic and social spheres of life in the Kemerovo region [15-16]. It's up to authorities.

Acknowledgement

The research was carried out with the plan of research work of IEIE SB RAS, project "Driving forces and mechanisms of cooperation and integration processes in the economy of Siberia" (№ 121040100279-5).

\section{References}

1. V. Kryukov, Yu. Fridman, G. Rechko, E. Loginova, ECO J., 11, 8 (2018)

2. J. Esteban, Reg. Sci. Urban. Econ, 30, 353 (2000)

3. H. W. Herzog, R.J. Olsen, J. Regional. Sci., 19, 393 (1979)

4. D. C. Knudsen, Socio. Econ. Plan. Sci., 34, 177 (2000)

5. H. W. Richardson, Int. Regional. Sci. Rev., 3, 1 (1978)

6. Iu. A. Fridman, G. N. Rechko, Probl. Econ. Transit., 55, 30 (2012)

7. Yu. Fridman, G. Rechko, E. Loginova, J. Min. Sci+, 51, 924 (2015)

8. Global and Russian Energy Outlook 2019 / ed. A.A. Makarov, T.A. Mitrova, V.A. Kulagin (ERI RAS - MSM Skolkovo, Moscow, 2019)

9. L. S. Plakitkina, ENERGY-21 - Sustainable Development \& Smart Management, 209 (2020)

10. Yu. A. Plakitkin, L. S. Plakitkina, K. I. Dyachenko, J. Mining, 10, 54 (2020)

11. Renewables 2020, Analysis and forecast to 2025 (IEA, 2020, https://www.iea.org/reports/renewables-2020)

12. Coal 2020, Analysis and forecast to 2025 (IEA, 2020, https://www.iea.org/reports/coal-2020) 
13. Y. Fridman, E. Loginova, G. Rechko, E3S Web of Conferences, 134, 03002 (2019)

14. V.A. Kryukov, Yu.A. Fridman, V.M. Markova, G.N. Rechko, E.Yu. Loginova, IOP Conference Series: J. of Phys., 1749, 012043 (2021)

15. V. Kryukov, A. Sevastyanova, A. Tokarev, V. Shmat, Econ. Reg., 13, 93 (2017)

16. V. A. Kryukov, Yu. A. Fridman, G. N. Rechko, E. Yu. Loginova, Kuzbass in a New Age (IEIE SB RAS, Novosibirsk, 2020) 